MATEC Web of Conferences 9, 01002 (2013)

DOI: $10.1051 /$ matecconf/20130901002

(C) Owned by the authors, published by EDP Sciences, 2013

\title{
A risk-informed appraisal of prescriptive building separation regulations in Switzerland
}

\author{
Jakob Studhalter
}

\author{
Basler \& Hofmann AG Zurich, Switzerland
}

\begin{abstract}
In Switzerland, prescriptive requirements apply to minimum separation distances between buildings in order to prevent building-to-building fire spread. These requirements are formulated by the regulatory body, for ease of use and enforcement, in a very simple manner: $10 \mathrm{~m}$ minimum separation distance between buildings, if both buildings have combustible exterior linings, $7.5 \mathrm{~m}$ if only one building has a combustible exterior lining, and $5 \mathrm{~m}$ if both buildings have non-combustible exterior linings. However, no quantitative guidance is given on how to reduce these distances, e.g. in cases where existing buildings are involved. In this paper, an overview on design methods for calculating separation distances in order to prevent fire spread between buildings is given. A model is described to calculate the probability of fire spread between buildings at several distances, taking into account relevant uncertainties. It appears that there is a 1 in 20 chance that a combustible exterior building lining can ignite if exposed to a burning building (room fire conditions) at a distance of $10 \mathrm{~m}$, and a 1 out of 3 chance if at a distance of $5 \mathrm{~m}$. The level of risk implicitly accepted by the Swiss fire codes is discussed, and a method is presented on how to derive separation distances imposing an equal level of risk for different building geometries and occupancies.
\end{abstract}

\section{INTRODUCTION}

In Switzerland, prescriptive requirements apply to minimum separation distances between buildings in order to prevent building-to-building fire spread. These requirements are formulated by the regulatory body, for ease of use and enforcement, in a very simple manner: $10 \mathrm{~m}$ minimum separation distance between buildings, if both buildings have combustible exterior linings, $7.5 \mathrm{~m}$ if only one building has a combustible exterior lining, and $5 \mathrm{~m}$ if both buildings have non-combustible exterior linings. Reduced requirements apply to single-family dwellings: $7 \mathrm{~m}, 6 \mathrm{~m}$, and $4 \mathrm{~m}$ respectively [1].

These requirements cannot be met in every case, e.g. between existing buildings. On the other hand, land of development is becoming short in Switzerland, and reduced distances between buildings are desirable in many cases. Quantitative guidance on how to reduce separation distances is not available in the relevant Swiss guidelines, however. This paper reviews design methods for this purpose, and also analyses the level of risk implicitly accepted by the prescriptive Swiss requirements.

\section{DESIGN METHODS REVIEW}

The Swiss fire codes [1] require minimum distances for building separation as described above. If these requirements cannot be met, the following compensation measures are recommended by the codes:

- fire resistance rating for exterior walls

- additional masonry layers on the inside of exterior walls

- confine areas of combustible exterior linings / apply non-combustible linings

- fire resistance rating for doors, windows

This is an Open Access article distributed under the terms of the Creative Commons Attribution License 2.0, which permits unrestricted use, distribution, and reproduction in any medium, provided the original work is properly cited. 


\section{MATEC Web of Conferences}

- window covers

- no windows directly opposed to each other

- fire resistant cladding of aprons.

No quantitative guidance is given, however, for the application of these compensation measures. Typically, local fire authorities would require one or several compensation measures depending on the involved buildings, without quantitative justification.

Other prescriptive fire safety codes specify minimum separation distances depending on fire resistance ratings of the exterior walls and opening sizes. Such requirements are based on analytical calculations of the heat flux emitting from the windows of a burning compartment. A method for the analytical design of building separation distances is given by the Fire Engineering Design Guide [2]. This method basically consists of the calculation of the radiant heat flux emitting from the openings of a burning compartment. The radiant heat flux $q_{r}\left(\mathrm{~kW} / \mathrm{m}^{2}\right)$ is given by

$$
q_{\mathrm{r}}=k \Phi F_{f} \varepsilon \sigma\left[\left(273+T_{f}\right)^{4}-\left(273+T_{r}\right)^{4}\right]
$$

where $k$ is the radiation reduction factor (-), $\Phi$ the configuration factor (-), $F_{f}$ the facade factor for consideration of multiple openings of a fire compartment $(-), \varepsilon$ the emissivity of emitting and absorptivity of receiving surface (-), $\sigma$ the Stefan-Boltzmann constant $\left(56.7 \times 10^{-12} \mathrm{~kW} / \mathrm{m}^{2} \mathrm{~K}^{4}\right), T_{f}$ the temperature of the emitting surface (fire temperature, ${ }^{\circ} \mathrm{C}$ ), and $T_{r}$ the temperature of the receiving surface $\left({ }^{\circ} \mathrm{C}\right.$ ). It is proposed that the radiant heat flux not exceed $12.5 \mathrm{~kW} / \mathrm{m}^{2}$ at the receiving facade if the facade consists of combustible (cellulosic) material, so piloted ignition is prevented. $30.0 \mathrm{~kW} / \mathrm{m}^{2}$ is proposed as a design value if the facade is made of non-combustible material. Using design values for piloted ignition at the receiving facade pays reference to the fact, that some kind of high-temperature ignition source, such as glowing embers, may be present at any time. On the other hand, using design values for spontaneous ignition would be unsafe.

Ranges of values for the variables in Eq. (1) are given by the Fire Engineering Design Guide and the following values are recommended for the calculation of the radiant heat flux [2]: Radiation factor $k-1.0$ (for cases where no fire resistant glazing in place); Emissivity $\varepsilon-0.9$; Fire temperature $T_{f}-1000{ }^{\circ} \mathrm{C}$. Assuming a temperature of the receiving surface $T_{r}=20^{\circ} \mathrm{C}$, a radiating area of $2 \mathrm{~m} \times 11 \mathrm{~m}$ is necessary in order to produce a heat flux of $12.5 \mathrm{~kW}^{2}$ at a distance of $7.5 \mathrm{~m}$. NFPA 80A [3] provides tabulated values for building separation distances, depending on the percentage of opening areas in the exterior wall and severity classes regarding fire load and interior wall and ceiling finishes. Separation distances are defined so that irradiation at the opposing facade does not exceed $12.5 \mathrm{~kW} / \mathrm{m}^{2}$. Taking the same configuration as in the example above, a minimum separation distance of $9 \mathrm{~m}$ would be necessary for buildings with moderate severity of fire load and interior wall and ceiling finishes (NFPA 80A assumes $178.6 \mathrm{~kW} / \mathrm{m}^{2}$ radiation intensity for moderate exposure, which corresponds to a fire temperature of $1059^{\circ} \mathrm{C}$ assuming an emissivity of 1.0 ).

Furthermore, NFPA 80A allows reduction of the tabulated distances depending on additional protection measures such as fire resistive walls and glazings or automatic sprinkler systems.

The design methods presented in the Fire Engineering Design Guide and NFPA specify separation distances based on radiation analyses. Direct flame contact and convective heat transfer are negligible, as long as a minimum distance between the buildings of approximately $1 \mathrm{~m}$ is obeyed. Also, both methods do not consider flame protection outside the window. According to the Fire Engineering Design Guide [2] this assumption is reasonable since the temperature of the flame protection is much less than within the fire compartment. Cheng and Hadjisophoclous however show in a recent work [4] that radiation from flame protection above the window can be more severe than radiation from the window itself. They also present a method for calculating the radiation, taking into account this fact. It should be mentioned, however, that flames do project out of a window for a few minutes only during a fire. 


\section{FIRE SPREAD MODEL}

A model for estimating the probability of fire spread between buildings has been established based on the design method given by the Fire Engineering Design Guide [2] as described above. Monte Carlo simulations have been conducted with the risk analysis software "@Risk", using the Latin Hypercube Sampling Method with 100000 iterations per simulation, in order to calculate the probability of the radiant heat flux $q_{r}$, emitting from the openings of a burning compartment exceeding the minimum heat flux for ignition $q_{\min }$ at opposing façades at several distances. The radiant heat flux $q_{r}$ from the burning compartment is calculated according to Eq. (1). The input variables are described in the following.

\section{Radiation reduction factor $k$}

As radiation reduction factor $k$, a value of 1.0 is used, since in standard cases, i.e. when separation distances are obeyed, no fire resistant glazing is in place, and normal glasses break and fall out within seconds after flashover.

\section{Configuration factor $\Phi$}

The configuration factor $\Phi(-)$ is given by

$$
\Phi=\frac{2}{\pi}\left[\frac{X}{\sqrt{1+X^{2}}} \tan ^{-1}\left(\frac{Y}{\sqrt{1+X^{2}}}\right)+\frac{Y}{\sqrt{1+Y^{2}}} \tan ^{-1}\left(\frac{Y}{\sqrt{1+Y^{2}}}\right)\right]
$$

where $X=\mathrm{H} / 2 R$ and $Y=W / 2 R$, and herein $H$ is the height of a rectangle containing all emitting openings (windows), $W$ is the width of this rectangle, and $R$ is the distance between the emitting and receiving surfaces, i.e. between the two opposing facades. This configuration factor applies to parallel orientated facades.

$H$ and $W$ are geometrical building features and therefore depend on architectural aspects. Distribution values which could be processed directly were not found in the literature. Thus, a survey has been conducted in order to obtain the relevant data [5]. Ten recent projects of a Swiss designing company with a total of 49 fire compartments have been analysed. In terms of $W$, a fair agreement to the field data was achieved by using a Beta-General function with a minimum of $0 \mathrm{~m}$, a maximum of $50 \mathrm{~m}$, and shape parameters $\alpha 1=2.5$ and $\alpha 2=10.4$. For $H$, histogram distributions as shown in Fig. 1 are defined, in order to reproduce the data accumulation at approximately $1.75 \mathrm{~m}$ opening height as best as possible. Figure 1, to the left, shows the distribution if all occupancies are considered. The distribution to the right shows the distribution when only residential buildings are considered. The distributions are of similar shape, with $H$ confined to $2.3 \mathrm{~m}$ for residential buildings.

\section{Facade factor $\boldsymbol{F}_{f}$}

The facade factor determines the actually open area inside the above described rectangle on the facade $(H \times W)$. A facade factor $F_{f}=1$, for example, tells that the whole considered area consists of window openings. In an area $H \times W$ with $F_{f}=0.6,60 \%$ consist of windows and $40 \%$ of exterior walls between the windows, etc. Field data for $F_{f}$ fits best to a Beta-General function with a minimum of 0.16 , a maximum of 1 , and shape parameters $\alpha 1=1.9$ and $\alpha 2=1.5$.

\section{Emissivity $\varepsilon$}

The Fire Engineering Design Guide [2] recites values for the emissivity $\varepsilon$ from 0.5 up to 1.0 and recommends to use a "conservative" value of 1.0 or a "reasonable" value of 0.9 for general cases. In special cases, e.g. when a fire contains a lot of plastics, the emissivity can rapidly decrease and drop 

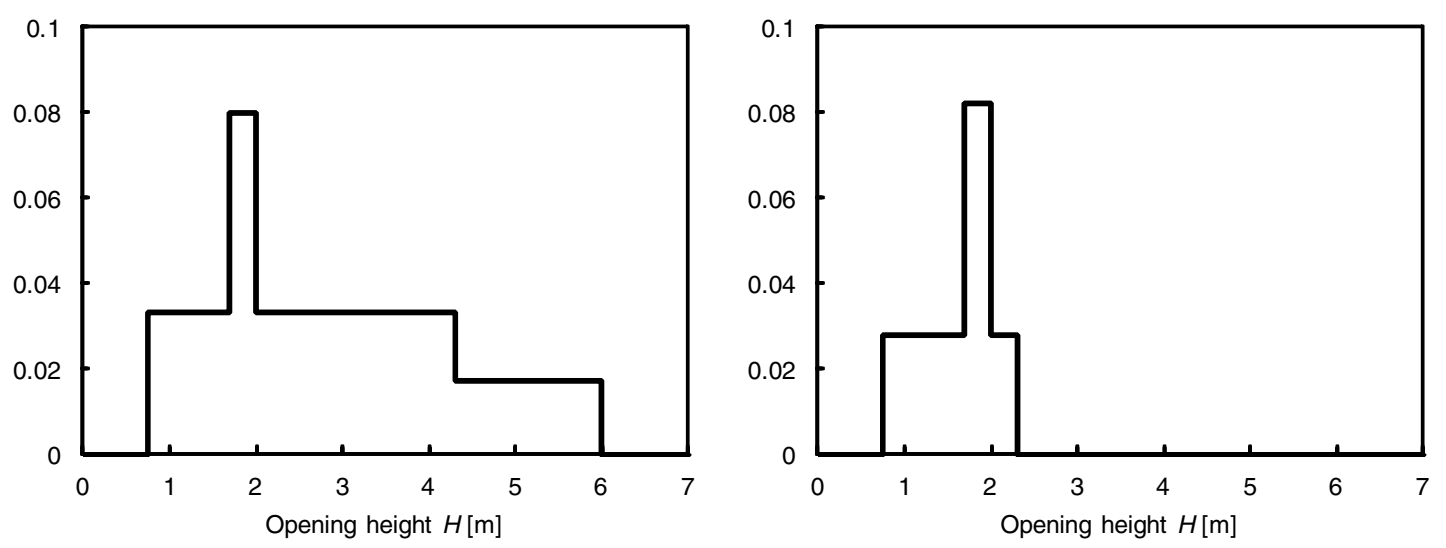

Figure 1. Relative frequency distribution graphs for the input variable H: all occupancies (left) and residential occupancies only (right).

to a value of 0.05 . In order to reproduce this range, a Beta-Pert distribution is used with the boundaries 0.05 / 0.9 / 1.0 (minimum / most likely / maximum).

\section{Fire temperature $T_{f}$}

A lot of data sets exist on recorded fire temperatures, and there are also methods to predict the fire temperature. The Fire Engineering Design Guide [2] provides an overview and reports temperatures between $800^{\circ} \mathrm{C}$ and $1200^{\circ} \mathrm{C}$. A Beta-Pert distribution is used with the boundaries $750{ }^{\circ} \mathrm{C} / 1000^{\circ} \mathrm{C} /$ $1250^{\circ} \mathrm{C}$ (minimum / most likely / maximum).

\section{Temperature of the receiving surface $T_{r}$}

The temperature of the receiving surface corresponds basically with the outside ambient temperature. For Swiss conditions, a normal distribution with a mean value of $15^{\circ} \mathrm{C}$ and a standard deviation of $8{ }^{\circ} \mathrm{C}$ represents the occurring temperatures realistically.

\section{Minimum heat flux for ignition $\boldsymbol{q}_{\min }$}

The minimum heat flux for ignition is the heat flux, below which ignition under practical conditions cannot occur. Literature values for wood and wood-based products vary between $10 \mathrm{~kW} / \mathrm{m}^{2}$ and $15 \mathrm{~kW} / \mathrm{m}^{2}$ for wood species and up to $19.7 \mathrm{~kW} / \mathrm{m}^{2}$ for particle board [6]. A recommended value for the use in design calculations is, as mentioned in the section above, $12.5 \mathrm{~kW} / \mathrm{m}^{2}$ for wood based products. A Beta-Pert distribution is used with the boundaries $10 \mathrm{~kW} / \mathrm{m}^{2} / 12.5 \mathrm{~kW} / \mathrm{m}^{2} / 19 \mathrm{~kW} / \mathrm{m}^{2}$ (minimum / most likely / maximum).

\section{Dependencies}

The obtained field data for $H, W$, and $F_{f}$ have been plotted against each other in order to determine potential dependencies [5]. Slight dependencies were made out between $H$ and $W$ (correlation coefficient $\approx 0.2$ ), as well as $F_{f}$ and $H$ (correlation coefficient $\approx 0.1$ ), but not between $F_{f}$ and $W$. Corresponding correlation coefficients are introduced into the model. Furthermore, the Fire Engineering Design Guide [2] points to a dependency between the fire temperature $T_{f}$ and the emissivity $\varepsilon$. Unfortunately, there is no statistical data readily available. In order to reproduce a dependency, a 
correlation coefficient of 0.5 is introduced into the model. Apart from these, no other dependencies have been considered, i.e. correlation coefficients are 0 .

Table 1. Probability of emitting radiation $\mathrm{q}_{r}$ exceeding the minimum heat flux for Ignition $\mathrm{q}_{\text {min }}$ at the opposing façade at distances required by Swiss fire codes.

\begin{tabular}{llllllll}
\hline & \multicolumn{4}{c}{ Distance between buildings $R$} \\
\cline { 2 - 4 } \cline { 7 - 9 } & \multicolumn{3}{c}{ Standard distances } & & \multicolumn{3}{c}{ Reduced distances } \\
\cline { 2 - 4 } \cline { 7 - 9 } & $10 \mathrm{~m}$ & $7.5 \mathrm{~m}$ & $5 \mathrm{~m}$ & & $7 \mathrm{~m}$ & $6 \mathrm{~m}$ & $4 \mathrm{~m}$ \\
\hline All occupancies & 0.06 & 0.15 & 0.36 & & 0.18 & 0.25 & 0.49 \\
\hline Residential occupancies & 0.01 & 0.04 & 0.20 & & 0.06 & 0.11 & 0.34 \\
\hline
\end{tabular}

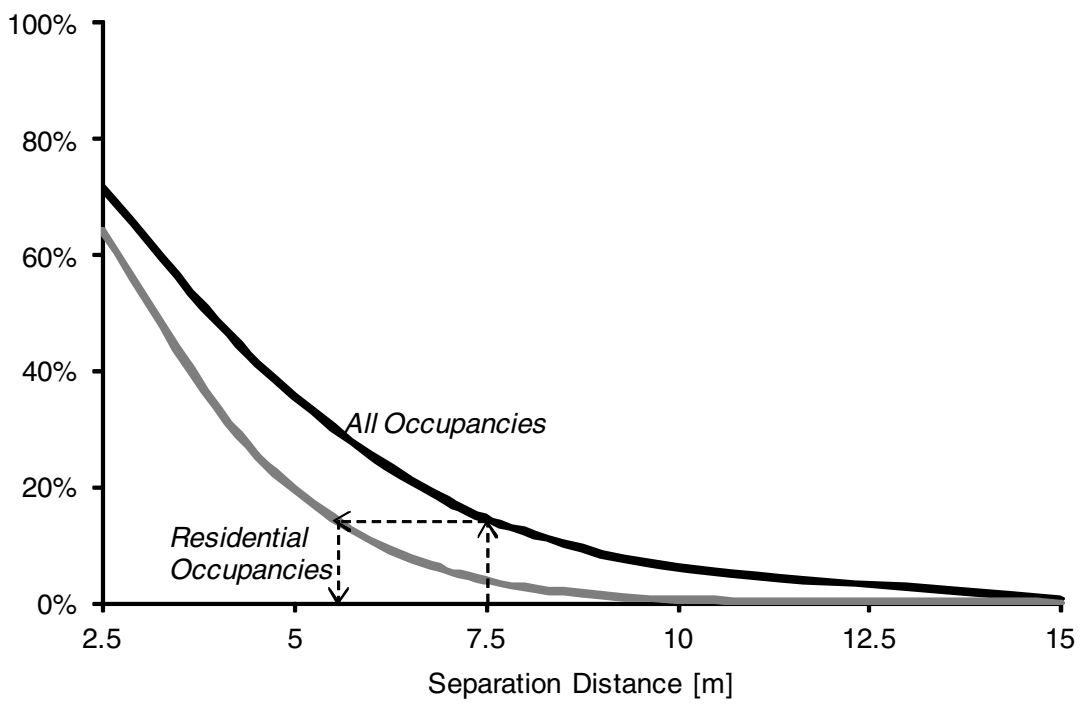

Figure 2. Percentage probability of emitting radiation $\mathrm{q}_{r}$ exceeding the minimum heat flux for ignition $\mathrm{q}_{\min }$ at the opposing façade.

\section{RESULTS}

The results of the Monte Carlo simulations with the fire spread model are given in Table 1. Black printed numbers are probabilities for the standard cases foreseen by the Swiss fire codes - standard distances (all occupancies) and reduced distances for single-family dwellings (residential occupancies). Grey printed numbers are given for completion. It appears that there is a 1 in 20 chance that a combustible exterior building lining (or combustible items inside an unprotected window) can ignite if exposed to a burning building (room fire conditions) at a distance of $10 \mathrm{~m}$, and a 1 out of 3 chance if at a distance of $5 \mathrm{~m}$.

Figure 2 shows these probabilities plotted on a graph, extended to separation distances from $2.5 \mathrm{~m}$ up to $15 \mathrm{~m}$. This graph allows determining required separation distances for the different occupancy classes for certain probabilities of not exceeding the minimum heat flux at the opposing facade. E.g., at a distance of $7.5 \mathrm{~m}$, there is a $15 \%$-probability of exceeding the minimum heat flux when all occupancies are considered. If only residential occupancies are considered, the separation distance could be reduced to approx. $5.5 \mathrm{~m}$, without increasing the probability of exceeding the minimum heat flux. 


\section{MATEC Web of Conferences}

\section{DISCUSSION}

The hazard of fire spread in form of the above derived probabilities is in the same order of magnitude for the two analysed categories at the corresponding distances (standard distances for general use, reduced distances for single-family dwellings).

An important aspect that requires discussion is the definition of the design value for irradiation at the receiving building. The Fire Engineering Design Guide [2], e.g., gives $30 \mathrm{~kW} / \mathrm{m}^{2}$ as a design value for buildings with non-combustible exterior walls, but recommends $12.5 \mathrm{~kW} / \mathrm{m}^{2}$ for buildings with combustible exterior walls. NFPA 80A [3] gives separation distances based on a design value of $12.5 \mathrm{~kW} / \mathrm{m}^{2}$ regardless of the exterior wall material, assuming that combustible building contents can ignite in any case. The prescriptive Swiss requirements distinguish three cases: 1) both buildings with combustible linings, 2) one with combustible and one with non-combustible linings, and 3) both buildings with non-combustible linings. Different "design criteria" implicitly underlie therefore. In the second case, a deterministic design scenario would be the same as in the first case - the exposed building has a combustible exterior lining. It is a matter of chance, however, which of the building in the second case is exposed to the fire $-50 \%$ the one with combustible linings, $50 \%$ the other one with non-combustible linings. From this point of view, it makes sense to subdivide into three categories. The hazard of ignition of building contents is not considered in this consideration, however.

The analysed prescriptive code requirements regulate the risk involved with building-to-building fire spread. Hazard considerations have been discussed above. However, in order to evaluate the risk, consequences have to be considered, too. Amongst others, building height, occupancy type and presence of automatic suppression systems influence consequences and therefore the risk. None of them are addressed in the Swiss prescriptive requirements.

It should be mentioned, that the data set of buildings used in the above described fire spread model consists of contemporary buildings. These buildings have fire resistant structures according to current code requirements. Older buildings and/or buildings without fire resistance - e.g. one-storey industrial buildings - are not considered. These buildings are much larger radiant heat sources if on fire. It would be sensible, to treat such buildings individually and design separation distances by means of analytical methods as referred to above.

\section{References}

[1] Schweizerische Brandschutzvorschriften VKF 2003, Vereinigung Kantonaler Feuerversicherungen VKF, Bern, Switzerland, 2005

[2] Spearpoint, M. (Ed.) et al., "Fire Engineering Design Guide", New Zealand Centre for Advanced Engineering, Christchurch, New Zealand, 2010

[3] NFPA 80A, "Recommended Practice for Protection of Buildings from Exterior Fire Exposures", National Fire Protection Association, Quincy MA, USA, 2007

[4] Cheng, H., Hadjisophocleous, G.V., "Experimental study and modelling of radiation from compartment fires to adjacent buildings", Fire Safety Journal 53, 43-62, 2012

[5] Studhalter, J., "Fire Safety Regulations on Distances between Buildings in Switzerland: A Risk Informed Analysis of the Radiant Fire Spread Component", Project Report, University of Canterbury, Christchurch, New Zealand, 2011

[6] SFPE Engineering Guide to Piloted Ignition of Solid Materials under Radiant Exposure, Society of Fire Protection Engineers, Bethesda, MD, USA, 2002 